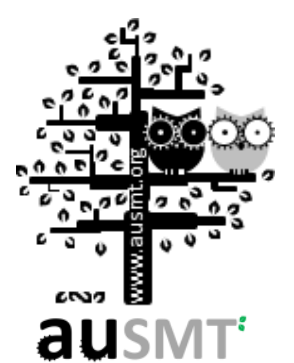

\title{
Sustainable Performance of Taiwanese Manufacturing Industries Over the Past Decade (2006-2015)
}

\author{
Tzu-Yu Lin', Sheng-Hsiung Chiu',2,*, and Helen Yang2 \\ ${ }^{1}$ Accounting School, Nanfang College of Sun Yat-Sen University, PR China \\ ${ }^{2}$ Market Intelligence \& Consulting Institute (MIC), Institute for Information Industry (III), Taiwan \\ (Received 16 October; Published on line 1 December 2017) \\ *Corresponding author email: mika.bear0809@gmail.com \\ DOI: $10.5875 /$ ausmt.v7i4.1658
}

\begin{abstract}
There has been a worldwide trend to mitigate greenhouse gas ( $\mathrm{CO} 2)$ emissions in a bid to combat climate change by developing new technologies on energy saving and renewable energy, and Taiwan is no exception. This study focuses on this important environmental and economic issue and proposes a sustainable performance model to investigate the performance behavior of Taiwanese manufacturing industries after the Kyoto protocol went into effect in 2005. We observe that sustainable performance during the past decade has risen slightly due to the effectiveness of energy-saving technologies and low-carbon energy structures. These two are effective strategies for guiding manufacturing industries with large quantity of $\mathrm{CO} 2$ emissions to improve their production activities, especially in the reduction of fossil fuel usage. Keep in mind that currently electricity portfolio in Taiwan is still dependent on coal combustion, though renewable energy is gaining its momentum starting this decade, and is integral to the future of the energy supply planning to pursue sustainable environment proposed by Taiwan government.
\end{abstract}

\section{Introduction}

Climate change, which mainly caused by great amounts of greenhouse gas (GHG) emissions, has led to the most severe living environment in the human history. A series of international initiatives on GHG emissions reduction has been pushed forward in the effort to limit the rising of Earth's temperatures. Kyoto Protocol was introduced in 2005 was the first important official documents established from the Conference of Parties under the United Nations Framework Convention on Climate Change. In 2016 last year, Paris Agreement was signed. It was also expected to be a legally binding international commitment, hopefully to be carried out between 2020 and 2030. However, in the past the resistance against emission control from developing countries, concerning the impacts on their economic development, has limited the effectiveness of international cooperation on climate change issues. From a strategical management viewpoint, the balance between economic development and environmental

www.ausmt.org

Copyright (C) 2017 International Journal of Automation and Smart Technology protection is essential for the success of GHG emissions control.

Taiwan, however, has not signed the Kyoto protocol nor the Paris Agreement due to political reasons, yet its government has continuously worked on effective strategies toward GHG emissions reduction, and has pushed for structural changes in energy supply, by promoting renewable energy in the hope of abating $\mathrm{CO} 2$ emissions along with the global trend of GHG emissions mitigation. At the same time, several projects and regulations on GHG emissions control have been carried out. Notably, the Renewable Energy Development Act and revision of Energy Management Act passed in 2009 were to provide incentives for elevating the proportion of sustainable energy in electricity generation. Taiwan has also declared its national determined contribution (NDC), to reduce GHG emissions by $20 \%$ in 2030 compared to their 2005 levels, in accordance of the COP21. In addition, the Greenhouse Gas Reduction and Management Act passed in 2015 has set GHG emission level in 2050 to be half of its 2005 level; industrial sector is also encouraged to adopt cleaning technologies to reduce GHG emission 
(Chiu, 2015). Building the emerging green industry is the main theme of the Green Energy Technology \& Industry Innovation Promotion Plan announced in 2017, of which is not only expected to accomplish the GHG emission reduction target, but push forward economic growth in Taiwan.

Taiwan has experienced rapid economic growth since 1970s, during which it also benefited from the global success of its manufacturing industries. Although the fundamental industrial structure has been gradually changing for some time, the industrial sector in Taiwan still plays an important role in the economy, accounting for more than $40 \%$ of the labor force and gross domestic product (GDP) in the past decade. Nevertheless, as companies in the industrial sector thrive, their production activities have also contributed to a large share of energy consumption and GHG emissions. Along the trend of environmental protection, an accurate evaluation of economic and environmental performance of industrial sector's framework, namely sustainable performance, has become the focus of policymakers, with respect to strategic plans to effectively reduce GHG emissions and increase GDP at the same time. This paper aims to assess the sustainable performance behavior of the Taiwanese manufacturing industry over the past decade (2006-2015). In this paper, we propose a data envelopment analysis (DEA) model with undesirable output to evaluate sustainable performance that incorporates economic and environmental performance indicators in a single evaluation framework.

\section{A Sustainable Performance Model}

\section{Data Envelopment Analysis with Undesirable Output}

The slacks-based measure, one of DEA models, was first proposed by Tone (2001) to be applied to the relative sustainable performance of the Taiwanese manufacturing industry. DEA models are especially useful when there are multiple input and output variables. Tone then has

Tzu-Yu Lin is an associate professor of Accounting at Nanfang college of Sun Yat-sen University. Her work focuses specifically on the accounting and economic issue of sustainable environment.

email: blackmallows@gmail.com

Sheng-Hsiung Chiu is an associate professor of Accounting at Nanfang college of Sun Yat-sen University and consultant at Market Intelligence \& Consulting Institute of Institute for Information Industry. He has participated in the project "National Energy Program-Phase II: project for promoting and managing energy strategies", and his main research interests are in the areas of Energy Economics and Performance Evaluation.

email: mika.bear0809@gmail.com

Helen Yang is an industrial analyst at Market Intelligence \& Consulting Institute of the Institute for Information Industry, Taiwan. Her work focuses on energy economics and the relevant areas. She is also a post-doc research fellow in Taiwan's National Energy Program (Phase II, NEP-II). email: Helen.Yang@micmail.iii.org.tw successfully expanded the idea to incorporate undesirable output, such as $\mathrm{CO} 2$ emission, a bad output of production activities in this study, in addition to the desirable output in the original setting. In Tone's model, an input matrix $X$ was selected to produce the output matrix $Y$, which was then divided into two categories, $Y^{G}$ and $Y^{B}$, where $Y^{G}$ represented the good (desirable) output as expected, and $Y^{B}$ denoted the bad (undesirable) output, which shall be avoided. In the proposed sustainable performance model, each manufacturing industry was treated as a decision-making unit (DMU).

The setting was as follows: Suppose there were $n$ DMUs $(j=1,2, \cdots, n)$ selected in the sample set. Each DMU had $m$ inputs, $s$ desirable outputs, and $u$ undesirable outputs. The input-output relationship of each DMU was denoted by $\left(x_{0}, y_{0}^{g}, y_{0}^{b}\right)$. The production possibility set was defined as:

$P=\left\{\left(x, y^{g}, y^{b}\right) \mid x \geq X \lambda, y^{g} \leq Y^{g} \lambda, y^{b} \geq Y^{b} \lambda, L \leq e \lambda \leq U, \lambda \geq 0\right\}$

where $\lambda$ was the intensity vector, and $L$ and $U$ were the lower and upper bounds of the intensity vector, respectively. Thus, the objective function of the proposed sustainable performance model, $\rho^{G E P}$, can be defined and modified as:

$$
\rho^{G E P}=\min \frac{1-\frac{1}{m} \sum_{i=1}^{m} \frac{s_{i o}^{-}}{x_{i o}}}{1+\frac{1}{s}\left(\sum_{r=1}^{s} \frac{s_{r}^{g}}{y_{r o}^{g}}+\sum_{r=1}^{n} \frac{s_{r}^{b}}{y_{r o}^{b}}\right)},
$$

subject to

$$
\begin{gathered}
x_{o}=X \lambda+s^{-} \\
y_{o}^{g}=Y \lambda-s^{g} \\
y_{o}^{b}=Y \lambda+s^{b} \\
L \leq e \lambda \leq U \\
s^{-}, s^{g}, s^{b}, \lambda \geq 0
\end{gathered}
$$

where the vectors $s^{-}$and $s^{b}$ correspond to excesses in inputs and bad (undesirable) output, respectively, while $s^{g}$ denoted the shortage of good (desirable) output. By design, when the DMU was efficient, $\rho^{G E P}=1$, and $s^{-}$, $s^{g}$, and $s^{b}$ of the DMU were zero. For an inefficient DMU, $\rho^{G E P}<1$, and it must look for any possible improvement by removing the excess of inputs and bad (undesirable) output. Furthermore, $w$ was a userspecified weight for good $\left(W^{g}\right)$ and bad output $\left(W^{b}\right)$, 
giving flexibility in dealing with the specific contribution of good and bad output to managerial insight. Equation (2) can be further modified as follows:

$$
\rho^{G E P}=\min \frac{1-\frac{1}{m} \sum_{i=1}^{m} \frac{s_{i o}^{-}}{x_{i o}}}{1+\frac{1}{s}\left(W^{g} \sum_{r=1}^{s} \frac{s_{r}^{g}}{y_{r o}^{g}}+W^{b} \sum_{r=1}^{u} \frac{s_{r}^{b}}{y_{r o}^{b}}\right)},
$$

where the user-specified weight for good $\left(W^{g}\right)$ and bad output $\left(W^{b}\right)$ were calculated by $W^{g}=w^{g} /\left(w^{g}+w^{d}\right)$ and $W^{b}=w b /\left(w^{g}+w^{d}\right)$.

\section{Input and Output Variable Selection}

The coefficient of $\mathrm{CO} 2$ emission, labor productivity, and energy productivity are commonly viewed as important variables when it comes to evaluating performance in energy and/or sustainable environment, yet conventionally they cannot be applied together in a single evaluation framework. One of the advantages of the DEA methodology is to provide a comprehensive framework for evaluation process with multiple inputs and outputs. Thus here we proposed a sustainable performance model that consider important parameters identified in previous literature, such as labor, capital, energy consumption, GDP, and $\mathrm{CO} 2$ emission, altogether for the Taiwanese manufacturing industries (Emrouznejad and Yang, 2016; Suzuki and Nijkamp, 2016; Valadkhani et al., 2016). We consider two inputs, labor and energy, one desirable output, GDP, and one undesirable output, CO2 emission in this paper. The definition of the input and output variables selected in the proposed sustainable performance model are summarized in Table 1.

\section{An Empirical Evaluation of Sustainable Performance}

\section{Data Source and Variable Definition}

In Taiwan, the six sectors: agriculture, energy, industrial, transportation, service, and housing are the main drivers for its economic development. Although the service sector is the most prominent sector in terms of GDP share, the industrial sector is of more concern because of its impact on the environment in terms of energy consumption and GHG emission. It is of interest then, from the managerial view, to find a new evaluation method for sustainable performance, which can subsequently contribute to a more comprehensive national sustainable policy with considerations of the environment and the economy at the same time. The main purpose of this paper is, therefore, to measure the sustainable performance of Taiwanese manufacturing industry, which is also the backbone of the industrial sector, and to identify the best performer in the period of post-Kyoto Protocol, from 2006 to 2015.

Each manufacturing industry in this paper is treated as a DMU, which uses two inputs in order to produce one desirable output and one undesirable output. Seventeen manufacturing industries are included in our sample and listed in Table 2. We use a panel dataset and the yearly data of the input and output variables collected over the period 2006-2015, obtained from the DirectorateGeneral of Budget, Accounting and Statistics, and the Bureau of Energy. With the data set, we are also able to identify the dynamic changes of the selected DMUs. The final sample data set consists of a total amount of 170 observations (DMUs).

\section{Input 1: Labor}

We use the yearly average number of employed staff for the "labor" variable. The data for this variable is obtained from the yearly labor force statistics from 2006 to 2015, created by the Directorate-General of Budget, Accounting, and Statistics. In this paper, because the amount of GDP produced by each manufacturing industry is an important output variable for evaluating the industries' economic performance, we use the ratio of GDP produced to the number of employed labor in each manufacturing industry, to approximate the per capita productivity.

\section{Input 2: Energy Consumption}

We use the kiloliter of oil equivalent of each energy category for the "energy" input variable. The data for this variable are from annual Energy Balance Sheet between 2006 to 2015, provided by the Bureau of Energy. In this paper, both the GDP and $\mathrm{CO} 2$ emission from each manufacturing industry are essential output variables for evaluating the industries' economic and environmental performance. We further categorize "energy" according the energy balance sheet, as in coal, crude oil and their products, natural gas, electricity and renewables.

\section{Input 3: Desirable Output: GDP}

The amount of GDP attributed to each manufacturing industry is included as the desirable output in the proposed model. The values are obtained from the annual National Accounts for the period of 2006-2015, organized by the Directorate-General of Budget, Accounting, and Statistics. To control for the inflation effect, we use 2011 as the base year and calculated real GDP from its nominal value. The Consumer Price Index (CPI) values listed in Table 3. 
Table 1. Definitions of the input and output variables.

\begin{tabular}{|l|l|l|l|}
\hline \multicolumn{1}{|c|}{ Criteria } & \multicolumn{1}{|c|}{ Name } & \multicolumn{1}{c|}{ Description } & \multicolumn{1}{c|}{ Measurement unit } \\
\hline \multirow{2}{*}{ Input } & Labor & Average labor employed in a specific year & Thousands \\
\cline { 2 - 4 } & Energy & Amount of energy used in a specific year & Kiloliter of oil equivalent \\
\hline Desirable output & GDP & Amount of GDP in a specific year & Million NT dollars \\
\hline $\begin{array}{l}\text { Undesirable } \\
\text { Output }\end{array}$ & $\mathrm{CO}_{2}$ emission & Amount of $\mathrm{CO}_{2}$ emission in a specific year & Ton \\
\hline
\end{tabular}

Table 2. A list of selected manufacturing industries as DMUs.

\begin{tabular}{clcl}
\hline DMU & \multicolumn{1}{c}{ Name } & DMU & \\
\hline 1 & Food, Beverage, and Tobacco & 10 & Plastic Products \\
2 & Textile, Apparel, and Accessories & 11 & Non-metallic Mineral Products \\
3 & Leather and Fur & 12 & Basic Metal Industries \\
4 & Wood, Bamboo, and Furniture & 13 & Fabricated Metal Products \\
5 & Pulp, Paper, and Paper Products & 14 & Machinery and Equipment \\
6 & Printing & 15 & Electrical and Electronic Machinery \\
7 & Chemical Materials & 16 & Transport Equipment \\
8 & Chemical Products & 17 & Miscellaneous Industries \\
9 & Rubber Products & & \\
\hline
\end{tabular}

Table 3. CPI values.

\begin{tabular}{lc}
\hline Year & Value \\
\hline 2006 & 107.10 \\
2007 & 106.64 \\
2008 & 103.87 \\
2009 & 104.00 \\
2010 & 100.00 \\
2011 & 100.54 \\
2012 & 102.02 \\
2013 & 103.75 \\
2014 & 107.15 \\
2015 & 107.85 \\
\hline
\end{tabular}

\section{Undesirable Output: $\mathrm{CO}_{2}$ Emission}

The most part of GHG emission from the byproducts of economic activities of each sector (Benhelal et al., 2013; Emrouznejad and Yang, 2016). For example, CO2 emission is the inevitable result of commodity production, whose power supply is mainly from traditional fossil fuel combustion. It is also deemed seriously detrimental to our climate and thus to be used in our sustainable performance model as the undesirable output. Unfortunately, the $\mathrm{CO} 2$ emission data for the Taiwanese manufacturing industries is not available from neither the National Greenhouse Gas Inventories under Environmental Protection Department, nor from the statistics of $\mathrm{CO} 2$ emission from fossil fuels summarized by the Bureau of Energy. We therefore use an estimate calculated from the consumption of various types of energies and their correspondent $\mathrm{CO} 2$ emission coefficient for each Taiwanese manufacturing industry.
The energy consumption data are obtained from the Energy Balance Sheet provided by the Bureau of Energy. The $\mathrm{CO} 2$ emission estimate is calculated according to the IPCC Guideline for National Greenhouse Gas Inventories (IPCC, 2006) as equation (4) below:

$$
C O_{2, i t}=E_{i t} \times N C V_{i} \times C E F_{i} \times C O F_{i} \times(44 / 12)
$$

where it denotes the $\mathrm{CO} 2$ emission from each type of energy, such as coal, crude oil, natural gas, and electricity, in year t. $E_{i t}$ denotes the total consumption of each type of energy in year t. $N C V_{i}$ denotes the net calorific value of each type of energy. $C E F_{i}$ denotes the carbon emission factor of each type of energy. $\mathrm{COF}_{i}$ denotes the carbon oxidation factor of each type of energy. The constant values of 44 and 12 are the molecular weights of $\mathrm{CO} 2$ and carbon, respectively.

\section{Empirical results}

In this paper, we proposed a sustainable performance model based on DEA framework with undesirable output to measure the relative sustainable performance of sectors and manufacturing industries in Taiwan in the past decade (2006-2015), 10 year into Kyoto Protocol. The evaluation results have sector-wise implications as well as economy-wise. The purpose of this data analysis is to measure the past efforts and discover the inefficient sources, in order to enhance the future sustainable performance. Through the model, we first obtain the averages of the sustainable performance scores of Taiwan's economy during 2006-2015, as shown in Table 4. In general, there was no significant change in the 
sustainable performance score (from 0.769 to 0.772 ) since 2006, which indicates that the effectiveness of the Table 4. The sustainable performance scores of five sectors between 2006 and 2015.

\begin{tabular}{|c|c|c|c|c|c|c|c|c|c|c|c|c|c|c|}
\hline Sectors & 2006 & 2007 & 2008 & 2009 & 2010 & 2011 & 2012 & 2013 & 2014 & 2015 & $\begin{array}{c}2006- \\
2010\end{array}$ & $\begin{array}{c}2011- \\
2015 \\
\end{array}$ & $\begin{array}{c}2006- \\
2015 \\
\end{array}$ & Rank \\
\hline Agriculture & & & & 1.000 & & & 1.000 & 1.000 & 1.000 & 1.000 & 1.000 & 1.000 & 1.000 & 1 \\
\hline Energy & 1.000 & 1.000 & 1.000 & 1.000 & 1.000 & 1.000 & 1.000 & 1.000 & 1.000 & 1.000 & 1.000 & 1.000 & 1.000 & 1 \\
\hline Industrial & 0.304 & 0.316 & 0.316 & 0.321 & 0.359 & 0.359 & 0.368 & 0.367 & 0.383 & 0.374 & 0.323 & 0.362 & 0.346 & 5 \\
\hline Transportation & 0.538 & 0.561 & 0.545 & 0.494 & 0.509 & 0.502 & 0.506 & 0.521 & 0.504 & 0.487 & 0.529 & 0.508 & 0.517 & 4 \\
\hline Service & 1.000 & 1.000 & 1.000 & 1.000 & 1.000 & 1.000 & 1.000 & 1.000 & 1.000 & 1.000 & 1.000 & 1.000 & 1.000 & 1 \\
\hline Overall & 0.769 & 0.775 & 0.772 & 0.763 & 0.774 & 0.772 & 0.775 & 0.778 & 0.777 & 0.772 & 0.771 & 0.774 & 0.773 & \\
\hline
\end{tabular}

Table 5. The sustainable performance scores of Taiwanese manufacturing industries between 2006 and 2015.

\begin{tabular}{|c|c|c|c|c|c|c|c|c|c|c|c|c|c|c|}
\hline Industries & 2006 & 2007 & 2008 & 2009 & 2010 & 2011 & 2012 & 2013 & 2014 & 2015 & $\begin{array}{c}2006 \\
- \\
2010\end{array}$ & $\begin{array}{c}2011 \\
- \\
2015\end{array}$ & $\begin{array}{c}2006 \\
- \\
2015\end{array}$ & Rank \\
\hline Food, Beverage, and Tobacco & 443 & 0.358 & 0.534 & 0.745 & 0.503 & 0.502 & 0.563 & 0.602 & 0.547 & 0.542 & 0.516 & 0.551 & 0.534 & 12 \\
\hline Accessories & 0.201 & 0.145 & 0.262 & 0.296 & 0.277 & 0.239 & 0.235 & 0.245 & 0.227 & 0.242 & 0.236 & 0.238 & 0.237 & 17 \\
\hline Leather and Fur & & 1.000 & 1.000 & 1.000 & 1.000 & 1.000 & 1.000 & 1.000 & 1.000 & 1.000 & 1.000 & 1.000 & 1.000 & 1 \\
\hline Wood, Bamboo, and Furniture & 1.000 & 1.000 & 1.000 & 1.000 & 1.000 & 1.000 & 1.000 & 1.000 & 1.000 & 1.000 & 1.000 & 1.000 & 1.000 & 1 \\
\hline Pulp, Paper, and Paper Products & 0.325 & 0.204 & 0.402 & 0.413 & 0.391 & 0.317 & 0.320 & 0.328 & 0.355 & 0.375 & 0.347 & 0.339 & 0.343 & 14 \\
\hline Printing & 1.000 & 1.000 & 1.000 & 1.000 & 1.000 & 0.987 & 0.927 & 0.892 & 0.846 & 0.785 & 1.000 & 0.887 & 0.944 & 7 \\
\hline Chemical Materials & 1.000 & 1.000 & 1.000 & 1.000 & 1.000 & 1.000 & 1.000 & 1.000 & 1.000 & 1.000 & 1.000 & 1.000 & 1.000 & 1 \\
\hline Chemical Products & 0.436 & 0.290 & 0.568 & 0.680 & 0.643 & 0.515 & 0.604 & 0.634 & 0.560 & 0.543 & 0.524 & 0.571 & 0.548 & 11 \\
\hline Rubber Products & 1.000 & 1.000 & 1.000 & 1.000 & 1.000 & 1.000 & 1.000 & 1.000 & 1.000 & 1.000 & 1.000 & 1.000 & 1.000 & 1 \\
\hline Plastic Products & 0.268 & 0.169 & 0.335 & 0.383 & 0.353 & 0.300 & 0.319 & 0.332 & 0.324 & 0.312 & 0.301 & 0.318 & 0.310 & 16 \\
\hline Non-metallic Mineral Products & 0.322 & 0.168 & 0.398 & 0.444 & 0.543 & 0.470 & 0.484 & 0.525 & 0.467 & 0.427 & 0.375 & 0.475 & 0.425 & 13 \\
\hline Basic Metal Industries & 0.666 & 0.573 & 0.794 & 0.760 & 0.775 & 0.660 & 0.653 & 0.881 & 0.922 & 0.898 & 0.713 & 0.803 & 0.758 & 9 \\
\hline Fabricated Metal Products & 0.368 & 0.262 & 0.305 & 0.308 & 0.292 & 0.315 & 0.304 & 0.335 & 0.326 & 0.316 & 0.307 & 0.319 & 0.313 & 15 \\
\hline Machinery and Equipment & 1.000 & 1.000 & 1.000 & 1.000 & 1.000 & 1.000 & 1.000 & 1.000 & 1.000 & 1.000 & 1.000 & 1.000 & 1.000 & 1 \\
\hline $\begin{array}{l}\text { Electrical and Electronic } \\
\text { Machinery }\end{array}$ & 1.000 & 1.000 & 1.000 & 1.000 & 1.000 & 1.000 & 1.000 & 1.000 & 1.000 & 1.000 & 1.000 & 1.000 & 1.000 & 1 \\
\hline Transport Equipment & 0.822 & 0.565 & 1.000 & 0.948 & 0.574 & 0.509 & 0.507 & 0.575 & 0.551 & 0.480 & 0.782 & 0.525 & 0.653 & 10 \\
\hline Miscellaneous Industries & 1.000 & 1.000 & 0.629 & 0.892 & 0.682 & 0.727 & 0.707 & 0.816 & 0.793 & 0.792 & 0.841 & 0.767 & 0.804 & 8 \\
\hline
\end{tabular}

various policies and energy-saving actions promoted is limited. For example, renewable energies account for zero to $4 \%$ of the energy supply mix between 2009 and 2016, which shows overdependence on fossil fuels in Taiwan's economy. It was not surprising to see that Taiwan's sustainable performance was relatively low.

Then, we also calculate each sector's sustainable performance score, as illustrated in Table 4. The sustainable performance score of the industrial sector over the past 10 years increased from 0.304 to 0.383 . Electricity and coal utilization dominated its energy consumption, which accounts for $90 \%$ of the consumption; the use of petroleum products significantly dropped from $15 \%$ to $5 \%$. It can be stated that the government's policy promotion or the voluntary adjustment of the energy consumption structure in the manufacturing process is quite effective for improving energy efficiency and reducing $\mathrm{CO} 2$ emissions, but it is not enough to accomplish the Taiwanese government's targeted goal. In the transportation sector, petroleum products are no doubt the monopolistic energy choice, especially gasoline for motor vehicles. There were almost 21 million mobile vehicles registered in 2015, according to Directorate General of Highways, Ministry of Transportation and 145 auSMT Vol.7 No.4 (2017) 
Communication. In light of our research finding, we suggest that hybrid and electric vehicles shall gain more importance, which is also part of the transportation transformation policy in Taiwan.

Finally, we try to explore the sustainable performance behavior of the manufacturing industries, to identify the best and worst performers, as shown in Table 5. It should be noted that three manufacturing industries-Textile, Apparel, and Accessories; Plastic Products; and Fabricated Metal Products-suffered from limited economic benefits while still produce mass $\mathrm{CO} 2$ emission, which may be the result of the energy-intensive nature of their manufacturing processes. Petroleum, fuel oil and diesel, main raw materials and energy input in manufacturing industry, all produce high $\mathrm{CO} 2$ emission. It then makes sense to make the manufacturing industry the first priority of Greenhouse Gas Reduction and Management Act, and to obligate them to improve their energy efficiency and rebate $\mathrm{CO} 2$ emissions to the required level set by the Environmental Protection Administration and the Bureau of Energy.

\section{Conclusions and Policy Discussion}

In this paper, we proposed a sustainable performance evaluation model based on DEA framework, considering both the economic and environmental simultaneously. In this model, two output variables, GDP as a desirable output and $\mathrm{CO} 2$ emission as undesirable output, are produced by investing labor force and consuming energy in each DMUs. We used data from 2006 to 2015 in Taiwan to construct the empirical model, and hope to shed lights on the performance of Taiwanese industries and their impact on the environment.

We can draw several policy implications from the evaluation results. First, we suggest that the government should pay more attention on industrial and transportation sectors because they relative underperformed in terms of their sustainable performance scores in past decade. Entrepreneurs should focus on the changes of the operation environment in the manufacturing industries and invest more in energysaving technologies and production innovation, to demonstrate their efforts regarding corporate social responsibility (CSR), as $\mathrm{CO} 2$ emission regulation in the global markets will become much stricter than before. Second, it is noted that electricity will be the main part of the energy consumption structure. A low-carbon electricity supply portfolio is an effective policy tool for decreasing $\mathrm{CO} 2$ emissions. However, it should be noted that the Taiwan government has set the electricity portfolio to be $20 \%$ from coal, $50 \%$ from natural gas, and $20 \%$ from renewable energies (which are mainly composed of solar and offshore wind turbines). It is a particularly hard task for the Taiwan government, since renewable energies have only accounted for $4 \%$ in recent years, and the government has also vowed to phase out nuclear energy soon. Developing a green energy industry is an important step to not only economic growth but also the acceleration of structural transformation of electricity supply.

\section{References}

[1] E. Benhelal, G. Zahedi, E. Shamsaei, and A. Bahadori, "Global strategies and potentials to curb $\mathrm{CO} 2$ emissions in cement industry," Journal of Cleaner Production, vol. 51, pp. 142-161, 2013. doi: 10.1016/j.jclepro.2012.10.049

[2] S.-H. Chiu, "An analysis of GHG emissions from Taiwan's industrial sector," International Journal of Automation and Smart Technology, vol. 5, pp. 197201, 2015. doi: 10.5875 /ausmt.v5i4.1060

[3] A. Emrouznejad and G.-L Yang, "CO2 emissions reduction of Chinese light manufacturing industries: A novel RAM-based global Malmquist-Luenberger productivity index," Energy Policy, vol. 96, pp. 397 410, 2016. doi: $10.1016 /$ i.enpol.2016.06.023

[4] IPCC, 2006. IPCC Guideline for National Greenhouse Gas Inventories. Retrieve from: http://www.ipccnggip.iges.or.jp/public/2006gl/vol2.html.

[5] S. Suzuki and P. Nijkamp, "An evaluation of energyenvironment-economic efficiency for EU, APEC and ASEAN countries: Design of a Target-Oriented DFM model with fixed factors in Data Envelopment Analysis," Energy Policy, vol. 88, pp. 100-112, 2016. doi: 10.1016/j.enpol.2015.10.007

[6] K. Tone, "A slacks-based measure of efficiency in data envelopment analysis," European Journal of Operational Research, vol. 130, no.3, pp. 498-509, 2001.

doi: 10.1016/S0377-2217(99)00407-5

[7] A. Valadkhani, I. Roshdi, and R. Smyth, "A multiplicative environmental DEA approach to measure efficiency changes in the world's major polluters," Energy Economics, vol. 54, pp. 363-375, 2016.

doi: $10.1016 /$ i.eneco.2015.12.018 